The results obtained herein appear to confirm the observations of other investigators $(1-7)$ that certain morphine protein conjugates can produce antibodies with the specificity, which may differ depending on the used hapten. Also indicated is the possibility of production of the morphine-3-glucuronide specific antibody which would be useful for developing a sensitive urine test for opiate users.

Acknowledgement: The authors wish to thank Sankyo Pharmaceutical Co. Ltd. for providing naloxone and oxymorphone.

\title{
REFERENCES
}

1) Spector, S. a.vd Parker, C.W.: Science 168, 1347 (1970); 2) Splcior, S.: J. Pharmacol. cxp. Ther. 178, 253 (1971); 3) Aduler, F.L. AND Lid, C.T.: J. Imman. 106, 1684 (1971); 4) Van Vunakis, H., Wasshiman, E. and Levine, L.: /. Pharmacol. exp. Ther, 180, 514 (1972); 5) Llute, R.K., Ullman, E.F., Goldsilin, A. and Herzinberg, L.A.: Nature 236, 93 (1972); 6) Wainer, B.H., Fitch, F.W., Rothberg, R.M. and FritD, J.: Science 176, 1143 (1972); 7) Wainer, B.H., Fitch, F.W., Frind, J. and Rothrerg, R.M.: J. Immun. 110, 667 (1973); 8) KoIDA, M. AND Kaneto, H.: Folia pharmacol, japon. 68, 265P (1972) (in Japanese); 9) Lowry, O.H., Rosebrough, N.J., Farr, A.L. and Ravdall, R.J.: J. biol. Chem. 193, 265 (1951)

\section{EXTERNAL CALCIUM IONS AND MECHANICAL RESPONSES OF THE AORTA ISOLATED FROM THE CHOLESTEROL- FED RABBIT}

\author{
Issei TAKAYANAGi, Masaatsu UCHIDA, Kejjiro TAKAGI \\ and Yasuo $\mathrm{ABE}$ : \\ Department of Chemical Pharmacolugy, Faculty of Pharmaceutical Sciences, \\ University of Tokyo, Bunkyo-ku, Tolyo, Japan and \\ *Kyorin Chemical Laboratories, Kita-ku, Tokyo, Japan \\ Accepted August 14, 1973
}

It has been reported that the endoplasmic reticulum in the aorta of the cholesterolfed rabbit became more extensive than that obscrved in normal smooth muscle cells (1). Tests have therefore been carried out to determine whether or not the endoplasmic reticulum appearing in the aorta of the cholesterol-fed rabbit plays an important role in contraction of the isolated aorta induced by agonists, while comparing the modes of action of agonists tested on the aorta isolated from the cholesterol-fed rabbit with those tested on the aorta from the normal rabbit.

One group of male albino rabbits was fed a diet containing $2 \%(w / w)$ cholesterol (Nihon Crea, CR-2) for 65 to 70 days. The other group was fed a diet without cholesterol. Total amount of serum cholesterol was estimated according to the method originally described by Zak (2) and Henley (3), was $1930.2 \perp 90.4 \mathrm{mg} / \mathrm{kg}$ (mean $\_$S.E.). The fact that the endoplasmic reticulum became more extensive in the aortic smooth muscle was con- 
firmed by electron microscopic observations.

After sacrificing a rabbit ( 3.6 to $4.1 \mathrm{~kg}$ in body wt.) by a blow on the neck, a section of the thoracic aorta between the heart and the diaphragm was removed and helically cut strips were prepared according to the method of Furchgott (4). A piece of the aorta was suspended in a $30 \mathrm{ml}$ organ bath filled with the normal Locke Ringer's solution, kept at $32 \mathrm{C}$ and bubbled with air. The normal Locke Ringer's solution used herein contained, in one litre, $9.0 \mathrm{~g}$ of $\mathrm{NaCl}, 0.4 \mathrm{~g}$ of $\mathrm{KCl}, 0.2 \mathrm{~g}$ of $\mathrm{CaCl}_{2}, 0.2 \mathrm{~g}$ of $\mathrm{MgCl}_{2}, 0.5 \mathrm{~g}$ of $\mathrm{NaHCO}_{3}$ and $0.5 \mathrm{~g}$ of glucose. Responses of the aorta to drugs were isotonically recorded. A concentration action curve of an agonist was cumulatively obtained: first, the curve was obtained in the normal Locke Ringer's solution, then in the Ca-free Locke Ringer's solution after 60 min incubation of the same aorta with the Ca-free Locke Ringer's solution. Ca-free Locke Ringer's solution was made as follows; $\mathrm{CaCl}_{3}$ was omitted from the normal Locke Ringer's solution and $0.1 \mathrm{mM}$ GEDTA (glycoletherdiamine tetracetic acid) was added. The experimental results are expressed as a mean of 8 experiments.

TABLI 1. The $\mathrm{pD}_{2}$ values (mean -S.L.) and intrinsic activities (mean 1 S.E.) of the agonists tested on aortas, isolated from both normal and cholesterol-fed rabbits, suspended in the normal and Ca-free Locke Ringer's solutions.

\begin{tabular}{|c|c|c|c|c|c|c|c|c|}
\hline & \multicolumn{4}{|c|}{ Normal rabbit } & \multicolumn{4}{|c|}{ Cholesterol fed rabbit } \\
\hline & \multicolumn{2}{|c|}{ normal solution } & \multicolumn{2}{|c|}{ Ca-free solution } & normal & solution & \multicolumn{2}{|c|}{ Ca-free solution } \\
\hline & i.a.: & $\mathrm{pD}_{2}$ & i.a. ${ }^{*}$ & $\mathrm{pD}_{3}$ & i.a.* & $\mathrm{pD}_{2}$ & i.a.* & $\mathrm{pD}_{2}$ \\
\hline Phenylephrine & 1.00 & $6.5: 0.110$ & .410 .03 & $6.0 \mid 0.10$ & 1.00 & $6.8=0.10$ & $4 \div 0.07$ & $6.1 \pm 0.11$ \\
\hline Histamine & $1.1+0.08$ & $5.6 \div 0.110$ & $.1 \pm 0.02$ & 5.2 .0 .101 & $1.0 \div 0.09$ & $5.9 \pm 0.07$ & $.2 \pm 0.01$ & 5.610 .16 \\
\hline $\mathrm{KCl}$ & $0.7 \div 0.03$ & $2.6 \div 0.060$ & $.5 \div 0.03$ & $2.3 \pm 0.020$ & $.8 \ldots 0.07$ & $2.8 \mid 0.06$ & .5 .10 .03 & $2.2: 0.06$ \\
\hline Acetylcholine & $0.6 \perp 0.03$ & 6.010 .16 & 0 & $\cdots-$ & $.4+0.12$ & $5.6 \div 0.16$ & 0 & - \\
\hline
\end{tabular}

* i.a. intrinsic activity - the maximum response to a drug, the maximum response to phenylephrine in a normal solution.

Activity of an agonist was expressed as a $\mathrm{pD}_{2}$ value. The $\mathrm{pD}_{2}$ value represented the negative logarithm of the concentration $(\mathrm{g} / \mathrm{ml})$ of the agonist that induces a $50 \%$ contraction in the isolated aorta. The maximum action of the agonist is expressed as the intrinsic activity according to Ariens (5). Tabble 1 shows the $\mathrm{pD}_{2}$-values and intrinsic activilies of phenylephrine, histamine, $\mathrm{KCl}$ and acetylcholine tested on the aortas isolated from normal and cholesterol-fed rabbits which were suspended in the normal and Ca-free Locke Ringer's solution. No significant differences were observed among all the $\mathrm{pD}_{2}$-values and intrinsic activities tested on the normal aorta and those tested on the aorta from the cholesterol-fed rabbit. The intrinsic activities of acetylcholine and histamine were greatly reduced by removal of the external Ca-ions, however, phenylephrine and $\mathrm{KCl}$ elicited a markedly greater contraction of atorta suspended in Ca-free Locke Ringer's solution than did histamine or acclylcholine. Hudgins and Weiss (6) reported that the responses of the aorta to $\mathrm{KCl}\left(25 \mathrm{mM}\right.$ or ca. $\left.1.8 \cdot 10^{-3} \mathrm{~g} / \mathrm{ml}\right)$ were almost abolished by removal of the external $\mathrm{Ca}$ ions. The concentration of $\mathrm{KCl}$ necessary to produce the maximum con- 
traction of the aorta suspended in Ca-free Locke Ringer's solution was 1 to $2 \times 10^{-2} \mathrm{~g} / \mathrm{ml}$ in our experiments. The response to this high concentration of $\mathrm{KCl}$ still remained in Ca-free Locke Ringer's solution. The minor response to the lower concentrations in our experiments (for example, $2 \times 10^{-3} \mathrm{~g} / \mathrm{ml}$ ) was also almost completely abolished by removal of the external Ca-ions. The difference between our findings and that of the aforementioned is presumably due 10 the concentrations of $\mathrm{KCl}$. It can be concluded from our experimental results that the maximum actions of $\mathrm{KCl}$ and phenylephrine are less dependent on the external Ca-ions than are those of histamine and acetylcholine. Since the $\mathrm{pD}_{2}$-values and intrinsic activities of the agonists, even $\mathrm{KCl}$ and phenylephrine which were less dependent on the external $\mathrm{Ca}$ ions, were not significantly modified by administration of cholesterol to the test animal (Table 1), the endoplasmic reticulum observed in the aorta of the cholesterol-fed rabbit is considered not to play an important role such as $\mathrm{Ca}$ store in the contraction mechanism of the isolated aorta.

\title{
REFERENCES
}

1) Parkik, F. And Odiand, G.F.: Am. J. Paih. 48, 197 (1966); 2) Zak, B.: Am. Clin. Path. 27, 583 (1957); 3) Henley, R.G.: Analyst 28, 286 (1957); 4) FurChGotT, R.F.: In Methods in Medical Rescarch, Editcd by Bruner, D., Vol. 8, p. 177, Ycar Book Medical Publishers, Inc. Chicago (1960); 5) Ariens, E.J.: Molecular Pharmacology, Vol, 1, p. 137, Academic Press, New York \& London (1964); 6) Hudgins, P.M. And Weiss, G.B.: J. Pharmacol. exp. Ther. $159,91(1968)$

\section{EFFECT OF L-GLUTAMINE ON INDOMETHACIN-INDUCED GASTRIC LESIONS IN THE RAT}

\author{
Susumu OKABE, Kunimiki OHTSU, Koji TAKEUCHI and Kcijiro TAKAGI \\ Department of Chemical Pharmacology. Faculty of Pharmaccutical Science's, \\ University of Tokyo, Bunkyo-ku, Tokyo, Japan
}

Accepted October 29, 1973

In a previous study from this laboratory it was indicated that L-glutamine exerts a strong inhibitory effects on aspirin-induced gastric lesions in rats (1). Similar to aspirin, indoncthacin is well known to evoke a side effect of gastrointestinal damages in humans (2) and animals (3-5). Whether or not L-glutamine has a beneficial effect on gastric damage in rats as induced by indomethacin was thus investigated herein.

Male Donryu strain rats, weighing $165-175 \mathrm{~g}$ prior to experiments, were fasted for $24 \mathrm{hr}$ except for free access to water. Indomethacin $(20 \mathrm{mg} / \mathrm{kg})$, suspended in a trace of Tween 80, was given either i.p. or per os to intact or pylorus-ligated rats 10 min after the operation. The pylorus was ligated under ether anesthesia according to the standard method by Shay et al. (6). L-glutamine suspended in $1 \%$ carboxymethylcellulose (CMC) solution was given orally over a wide dose range ten min before indomethacin adminis- 